\title{
Concentration of $\mathrm{FeSO}_{4}$ spent solutions by membrane distillation
}

\author{
Marek Gryta \\ Szczecin University of Technology, Institute of Chemical and Environment Engineering, ul. Pułaskiego 10, 70-322 \\ Szczecin, Poland, e-mail: marek.gryta@ps.pl, fax (+48 91) 4494682
}

\begin{abstract}
The possibility of potential application of membrane distillation for the concentration of waste salt solutions has been presented in this work. It was found that the oxidation of iron compounds takes place during the process that was associated with the formation of a layer of oxides on the membrane surface. A fast decline of the permeate flux was observed due to the scaling phenomena. The problem of scaling was eliminated by the acidification with $\mathrm{H}_{2} \mathrm{SO}_{4}$ of the feed to the $\mathrm{pH}$ value of 2 .
\end{abstract}

Keywords: Membrane distillation, Wastewater, $\mathrm{FeSO}_{4}$.

Presented at VII Conference Wasteless Technologies and Waste Management in Chemical Industry and Agriculture, Międzyzdroje, 12 - 15 June, 2007.

\section{INTRODUCTION}

Diluted solutions of salts generated by the industry are usually difficult for the treatment; therefore, they are frequently discharged into the environment. This is the reason of the environmental damage caused by an increase of surface water salinity ${ }^{1}$. One of the proposed solutions to this problem could be the separation of salt in the solid state, which can be subsequently used as a raw material or subjected to a safe disposal. However, these methods have been rarely used due to the high costs associated with the concentration of such solutions. Moreover, the thermal methods (multi-stage flash evaporation) are primarily used for the concentration of brines.

Reverse osmosis (RO) can be employed for a preliminary concentration of saline wastewater. However, the degree of concentration of saline wastewaters by RO process is restricted, due to the considerable problems associated with the fouling and scaling phenomena ${ }^{2}$. Membrane distillation (MD) can be used for the treatment of wastewater to convert it into pure water and a saturated solution, which allows the crystallization of salt ${ }^{3}$.

$\mathrm{MD}$ is an evaporation process of the volatile components in the feed through non-wetted porous hydrophobic membranes. During the process a fraction of the membrane pores is filled by the feed, due to the solution/ membrane interaction ${ }^{3}$. Moreover, the presence of salts in the feed significantly affects the membrane wettability. As a consequence, the transport of solutes through the wetted pores from the feed to the distillate is possible $\mathrm{e}^{3-5}$.

Diluted Fe (II) sulphate (VI) solutions constitute a special type of saline wastewaters. These solutions are generated during the processes of metal etching or in the process of titanium white $\left(\mathrm{TiO}_{2}\right)$ manufacture ${ }^{6,7}$. Although $\mathrm{FeSO}_{4}$ is a well soluble salt, the spent solutions may additionally contain several sparingly soluble salts. The precipitation and deposition of the insoluble salts onto the membrane surfaces (scaling) is one of the major problems for all the membrane technologies ${ }^{2-7}$. Moreover, the formation of several types of the iron oxides from $\mathrm{Fe}(\mathrm{II})$ and $\mathrm{Fe}(\mathrm{III})$ salt solutions as a result of the oxidation followed by the hydrolysis is possible ${ }^{8}$. A fouling of the membrane surface caused by the iron oxides has been observed $^{2}$.
The oxidation reaction of $\mathrm{Fe}$ (II) salt solutions with oxygen can be presented by the chemical equation ${ }^{8}$ :

$2 \mathrm{Fe}^{2+}+3 \mathrm{H}_{2} \mathrm{O}+1 / 2 \mathrm{O}_{2}=2 \mathrm{FeOOH}+4 \mathrm{H}^{+}$

Unless the reaction conditions are controlled, the mixtures, rather than a monophase product result. Lepidocrocite, $\gamma-\mathrm{FeOOH}$ (orange) and goethite, $\alpha-\mathrm{FeOOH}$ (yellow-brown), are often found in the oxidation products. Goethite is one of the most thermodynamically stable form of iron oxides. The oxidation proceeds slowly below the $\mathrm{pH} 6$ and rises sharply above this value. The formation of intermediate greenish-blue, mixed Fe(II)$\mathrm{Fe}$ (III) phase (green rusts), predominates if the oxidation takes place under the conditions varying from weakly acidic to weakly alkaline:

$3 \mathrm{FeSO}_{4}+4.5 \mathrm{H}_{2} \mathrm{O}+0.25 \mathrm{O}_{2}=\mathrm{Fe}_{2}{ }^{\mathrm{II}} \mathrm{Fe}^{\mathrm{III}}(\mathrm{OH})_{5} \mathrm{SO}_{4}+$ $2 \mathrm{H}_{2} \mathrm{SO}_{4}$

If the concentration of the $\mathrm{Fe}^{2+}$ ions falls below the critical level, further oxidation leads to the decomposition of green rust and to the formation of goethite and/or lepidocrocite:

$2 \mathrm{Fe}_{2}{ }^{\mathrm{II}} \mathrm{Fe}^{\mathrm{III}}(\mathrm{OH})_{5} \mathrm{SO}_{4}+\mathrm{O}_{2}=6 \mathrm{FeOOH}+2 \mathrm{H}_{2} \mathrm{SO}_{4}$

The oxidation is kinetically hindered in the $\mathrm{pH}$ range from 2.5 to 4.

The oxidation of $\mathrm{FeSO}_{4}$ solution over the $\mathrm{pH}$ range of $4.0-7.5$ at elevated temperature $(358 \mathrm{~K})$ leads to hematite: $\alpha-\mathrm{Fe}_{2} \mathrm{O}_{3}$ (blood-red). This compound is extremely stable and comprises the final result of transformation of the other iron oxides ${ }^{8}$.

In this work the possibilities of application of the MD process for the concentration of spent $\mathrm{FeSO}_{4}$ solutions, from $\mathrm{TiO}_{2}$ manufacture and metal etching, were evaluated.

\section{EXPERIMENTAL}

A scheme of MD laboratory installation was described in a previous work ${ }^{3,6}$. This installation consists of two thermostatic loops, the feed and the distillate one, which were connected to the membrane module. The glass, silicone and PCV materials were used for the construction of the experimental set-up.

The MD module was equipped with the hydrophobic capillary polypropylene membranes (Accurel S6/2 PP, Microdyne - Germany), with outside/inside diameter equal 
to dout $/$ din $=2.6 \mathrm{~mm} / 1.8 \mathrm{~mm}$. The 24 membranes were assembled within the tubular housing $(22 \mathrm{~mm}$ of diameter) as a parallel bundle of capillaries, and the effective membrane area was equal to $149 \mathrm{~cm}^{2}$. The distillate temperature at the entrance of the module was kept at a constant level of $293 \mathrm{~K}$, whereas the feed temperature was varied in the range of $333-353 \mathrm{~K}$. The feed and the distillate streams flow counter-currently. The flow rate of the feed alongside the membrane surface was $0.2 \mathrm{~m} / \mathrm{s}$, whereas that of the distillate amounted to $0.019 \mathrm{~m} / \mathrm{s}$. The same hydraulic pressure $(16 \mathrm{kPa})$ of both streams was applied at the module inlet.

In this work the spent solutions of $\mathrm{FeSO}_{4}$ were prepared with the use of iron salt (mainly $\mathrm{FeSO}_{4} \cdot 7 \mathrm{H}_{2} \mathrm{O}$ ) formed as a by-product in the titanium white $\left(\mathrm{TiO}_{2}\right)$ manufacture process ${ }^{6}$ and the salt crystallised from the solutions generated during the processes of metal etching (ST1X steel). The salt obtained from the titanium white production, besides the iron compounds, also contained about $1 \mathrm{wt} . \%$ of the salts of other metals (Ti, $\mathrm{Mn}, \mathrm{Cu}, \mathrm{V}$, $\mathrm{Cr}$ and $\mathrm{Ni})^{6}$. The spent solution from metal etching was also used as a feed in the MD process. This solution contained 18.2 wt. $\% \mathrm{FeSO}_{4}, 2.5$ wt. $\% \mathrm{Fe}_{2}\left(\mathrm{SO}_{4}\right)_{3}, 0.15$ wt. $\% \mathrm{H}_{2} \mathrm{SO}_{4}$ and $\mathrm{Ni}, \mathrm{Mn}$ and $\mathrm{Cr}\left(1.8,2.0\right.$ and $2.3 \mathrm{~g} / \mathrm{dm}^{3}$, respectively). The concentrations of these compounds were measured using the standard colorimetric and titration methods ${ }^{1}$. The iron concentration was determined by the colorimetric method $(\lambda=512 \mathrm{~nm})$, using the reaction $\mathrm{Fe}^{2+}$ ions with 1,10-phenanthroline. The ferric ions were reduced to $\mathrm{Fe}^{2+}$ with hydroxylamine for the determination of the total iron.

The electrical conductivity of the investigated solutions was measured by a 6P Ultrameter (Myron L Company). The morphology and composition of the deposit layer formed on the membrane surface were studied using a Jeol JSM 6100 scanning electron microscopy (SEM) coupled with energy dispersion spectrometry (EDS).

\section{RESULTS}

The solutions prepared from salts crystallized from spent solutions, generated during the metal etching process, were used in the first stage of the studies of membrane distillation. An analysis of the composition of the prepared solutions demonstrated that these solutions contained besides the $\mathrm{Fe}^{2+}$ ions also the $\mathrm{Fe}^{3+}$ ions (about $20 \%$ ). After several hours of MD process operation, the amount of $\mathrm{Fe}^{3+}$ ions in the concentrated solution was increased up to $30 \mathrm{wt} . \%$ of the total iron.

The course of the concentration of iron salts solutions was presented in Fig. 1. It was found that the magnitude of the obtained permeate flux was decreasing with an increase in the feed concentration as a result of the changes of the driving force. The driving force for the mass transfer in the MD process is the vapour pressure difference across the membrane caused by both the existing temperature gradient and the composition of the solutions in the layers adjacent to the membrane ${ }^{3-7}$. An increase in the solute concentration causes a decline of the partial water vapour pressure, resulting in the reduction of the permeate flux. The partial vapour pressure increases exponentially with temperature, therefore an increase of the feed temperature causes a significant change of the

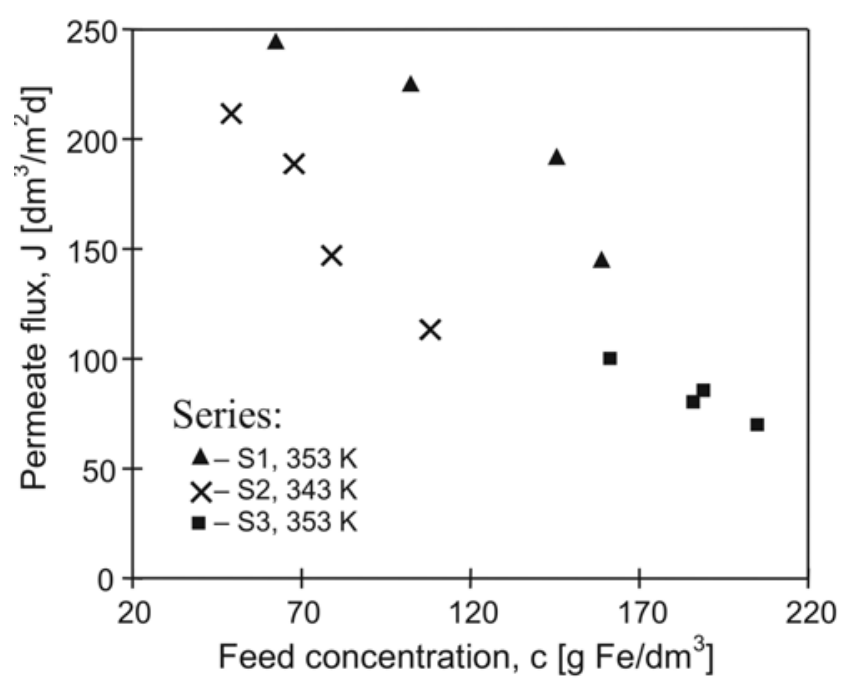

Figure 1. The influence of the feed concentration and temperature on the permeate flux. The feed - solution prepared from iron salts obtained from the metal etching process

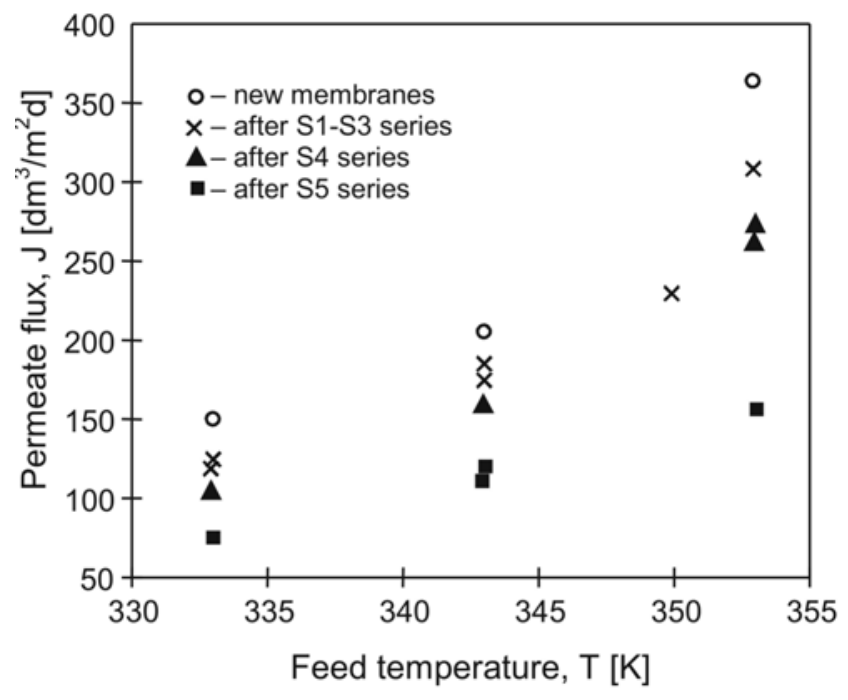

Figure 2. The influence of the feed temperature on the permeate flux in the MD process with tap water used as a feed (maximum permeate flux)

flux (Fig. 2). Therefore, a lower flux was obtained when the feed temperature was reduced from 353 to $343 \mathrm{~K}$ (Fig. 1 , series $\mathrm{S} 2$ ).

The retentates obtained from the S1 and S2 series were mixed, and the process of their concentration was continued in the S3 series (Fig. 1). After reaching the final concentration of $210 \mathrm{~g} \mathrm{Fe} / \mathrm{dm}^{3}$, the MD process was interrupted and the obtained retentate was cooled to $295 \mathrm{~K}$. This allowed to obtain the $676 \mathrm{~g}$ of salt crystals from $1 \mathrm{dm}^{3}$ of the retentate.

In the second stage of MD studies, the solutions prepared from a salt formed during $\mathrm{TiO}_{2}$ production were used as a feed. The obtained solution was turbid with a yellowish-green colour. The analysis of the composition of this solution demonstrated that the amount of the $\mathrm{Fe}^{3+}$ ions was close to the content of the $\mathrm{Fe}^{2+}$ ions. During $2-3 \mathrm{~h}$ of MD process operation, the amount of the $\mathrm{Fe}^{3+}$ ions in the concentrated solution was increased to a level of $60 \mathrm{wt} . \%$. As a result, the solution becomes darker and takes on a brown colour. The MD installation was open to atmosphere; therefore, the feed solution was contacted 
with air. As a result, the oxidation reaction of $\mathrm{Fe}^{2+}$ ions proceeded, as it was described in the Introduction part.

The presence of a large amount of suspended solids together with the formation of iron oxides caused a rapid decline of the yield of MD process. The concentration of $5 \mathrm{wt}$ \% solution of salt for a period of $6 \mathrm{~h}$ (Fig. 3, series $\mathrm{S} 4$ and S5) resulted in a decline of the permeate flux from 200 to $125 \mathrm{dm}^{3} / \mathrm{m}^{2} \mathrm{~d}$. The deposit formed on the feed side was a reddish-brown colour and exhibited a large adherence to the membrane surface.

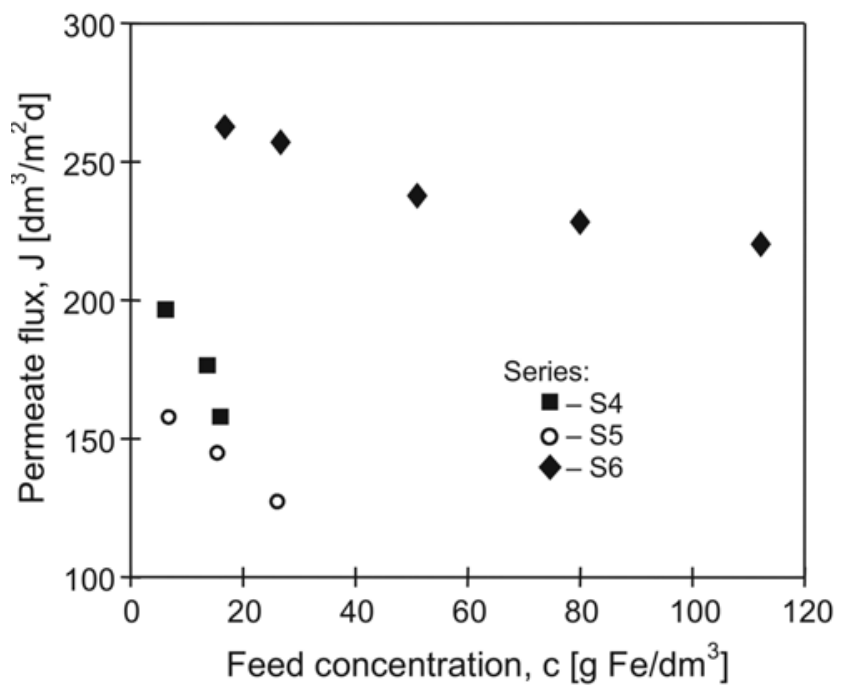

Figure 3. The influence of the feed concentration on the permeate flux. The feed - solution prepared from iron salts generated in $\mathrm{TiO}_{2}$ production

However, the formation of deposit on the membrane surface (scaling) caused a significant decline of the maximum yield of process (Fig. 2), which was determined using tap water. An essential decline in the yield has already been observed after the completion of the studies with the salt obtained from the metal eating process. However, in the case of the salt from $\mathrm{TiO}_{2}$ production, almost a three-fold decrease in the permeate flux was observed over a period of several times shorter $(6 \mathrm{~h})$.

The SEM examination confirmed that a significant amount of the crystallites was deposited on the membrane surfaces (Fig. 4). The composition of the formed deposit was analysed by the SEM-EDS method (Fig. 5). Besides the major component (Fe), small amounts of $\mathrm{Ti}, \mathrm{Cr}, \mathrm{Ca}, \mathrm{Ni}, \mathrm{P}$ and $\mathrm{Cl}$ were also determined. The formed deposit caused clogging of the evaporation surfaces, which leads to a decline of the modules efficiency. Additionally, the membrane surface becomes wetted in the places where the deposit was formed; hence, the liquid may penetrate into the pores. Therefore, the deposit formed on the membrane surface constitutes a principal factor impeding the possibility of the long-term MD module exploitation ${ }^{3,4}$.

It was found that the observed deposit can be removed from the membrane surface by rinsing the modules with a 2 - 5 wt. $\% \mathrm{H}_{2} \mathrm{SO}_{4}$ solution. The SEM examination confirmed that after rinsing the membrane surface was cleaned (Fig. 6), which enabled the recovery of the initial process efficiency. Subsequently, a new solution (5 wt.\%) of salt (from $\mathrm{TiO}_{2}$ production) was prepared and the sulphuric acid was added $\left(8 \mathrm{ml} 96 \% \mathrm{H}_{2} \mathrm{SO}_{4} / \mathrm{dm}^{3}\right)$ to this solution. As a result, the solution become clear and did

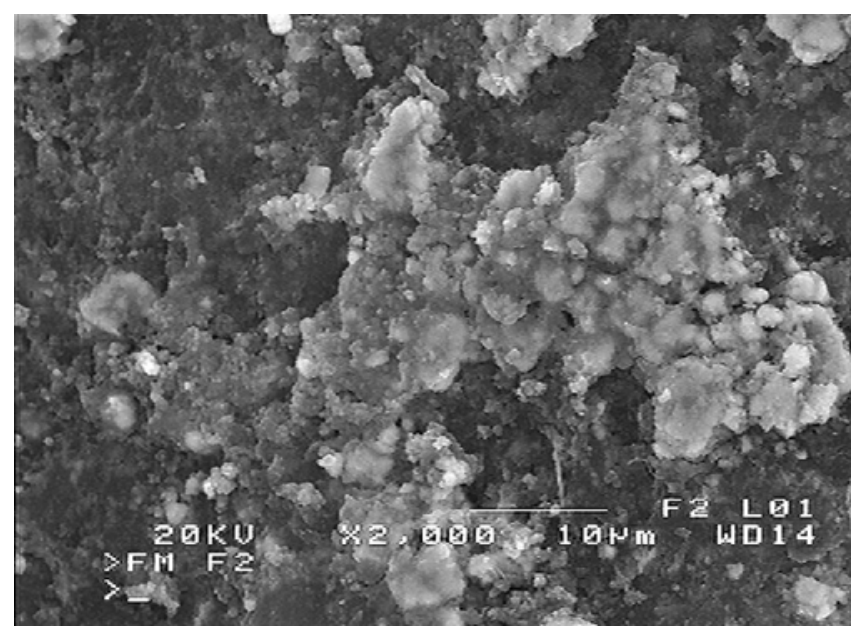

Figure 4. SEM image of the iron oxides deposit formed on the surface membranes during MD of the solutions prepared from the salt obtained from $\mathrm{TiO}_{2}$ production

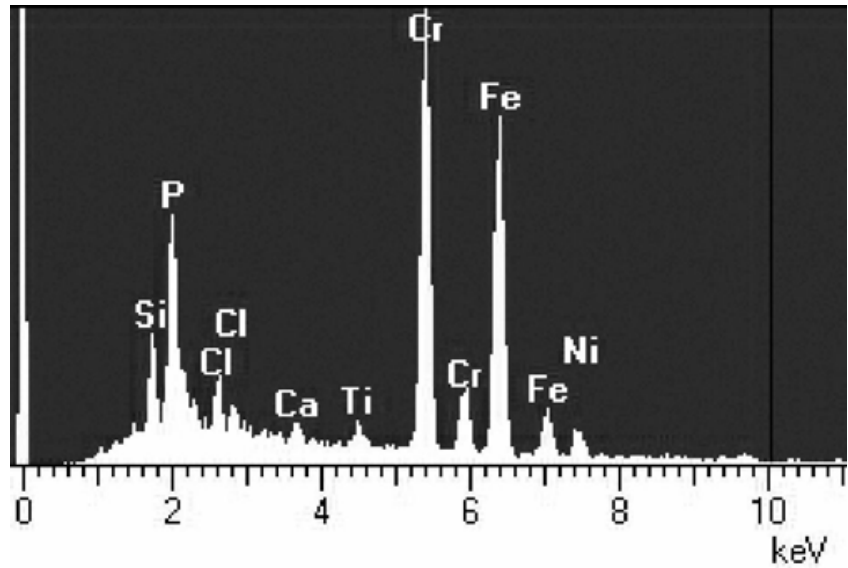

Figure 5. The result of the SEM-EDS analysis of the deposit formed on the membrane surface (Fig.4)

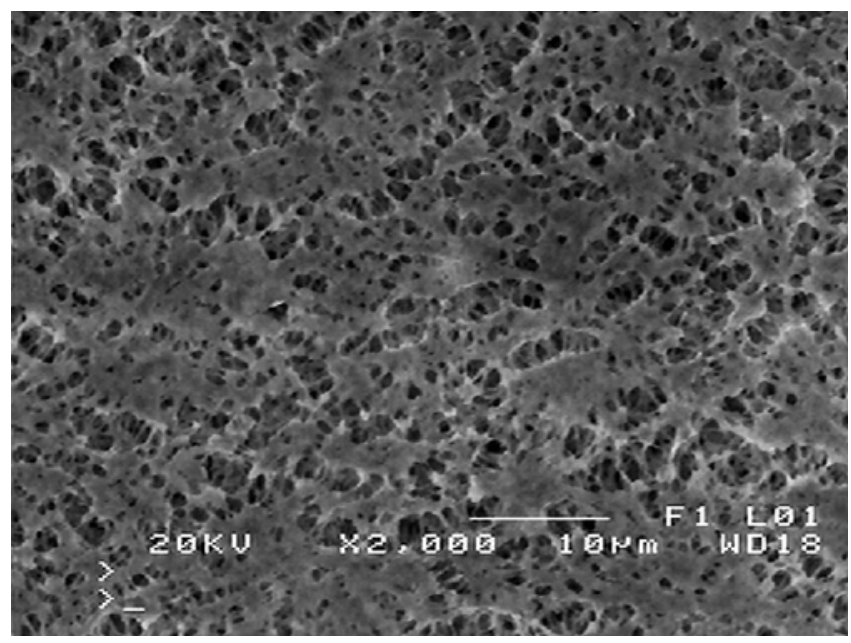

Figure 6. SEM image of Accurel PP S6/2 polypropylene membrane after rinsing by the sulfuric acid solution

not change colour during the membrane distillation. The results presented in Fig. 3 (series S6) indicate that the acidification of the feed solution allowed to achieve a high stability of process performance. A slight decrease in the permeate flux observed during the process resulted from a decrease in the water vapour pressure caused by an increase in the solute concentration. The spent solution from $\mathrm{TiO}_{2}$ production besides iron sulphates also con- 
tains sulphuric acid, which creates the possibility of using the MD process for the concentration of this effluent.

Finally the spent solution from metal etching was subjected to the concentration using a batch mode of the MD process. The three portions of this solution were concentrated from 82 to $177-205 \mathrm{~g} \mathrm{Fe} / \mathrm{dm}^{3}$. However, the permeate flux was reduced from 295 to $128 \mathrm{dm}^{3} / \mathrm{m}^{2} \mathrm{~d}$ as a fouling result. Probably the fouling occurred because the $\mathrm{H}_{2} \mathrm{SO}_{4}$ concentration level in the feed was too low $(0.15 \mathrm{wt} . \%)$. The initial efficiency was restored by rinsing the module with $5 \mathrm{wt} . \% \mathrm{H}_{2} \mathrm{SO}_{4}$ followed by water.

\section{CONCLUSION}

The spent solutions of iron salt can be concentrated in the MD process almost to the saturation state. This allows by a combination of MD with a crystallization process to carry out a continuous process of the concentration with a simultaneous recovery of crystalline salt.

During the concentration of iron salt solutions (e.g. $\mathrm{FeSO}_{4}$ ) a partial oxidation of the ions proceeds resulting in the formation of the iron oxides. The presence of these oxides in the feed favours the formation of the deposit on the membrane surface, and as a result, the yield of the MD process is rapidly decreasing. However, the acidification of the concentrated solution to a value of the $\mathrm{pH}$ below 2 allows to prevent the scaling phenomenon.

Rinsing of the membrane modules with a $2-5 \mathrm{wt}$.\% solution of $\mathrm{H}_{2} \mathrm{SO}_{4}$ results in the removal of the deposit of the iron oxides from the membrane surface, and as a consequence, the initial yield of the membrane module can be restored.

\section{LITERATURE CITED}

(1) Dojlido J. R., Best G. A.: Chemistry of water and water pollution, Ellis Horwood, Chichester, 1993.

(2) Singh R.: Hybrid membrane systems for water purification, Elsevier, Oxford 2006.

(3) Gryta M.: Solutes separation by membrane distillation process, Dissertation, Szczecin University of Technology, Szczecin, 2003.

(4) Alkalaibi A. M., Lior N.: Membrane-distillation desalination: status and potential, Desalination, 2004, 171, 111.

(5) Gryta M., Tomaszewska M., Karakulski K.: Wastewater treatment by membrane distillation, Desalination, 2006, 198, 67.

(6) Lewicki M., Gryta M.: Gaz desulfurization in the hybrid system absorption - membrane distillation, Pol. J. Chem. Technol., 2004, 4, 47.

(7) Tomaszewska M., Gryta M., Morawski A. W.: Recovery of hydrochloric acid from metal pickling solutions by membrane distillation, Sep. Purif. Technol., 2001, $22-23,591$.

(8) Cornell R. M., Schwertmann U.: The iron oxides, Wiley-VCH, Weinheim, 2003. 